\title{
Nondestructive Damage Detection Based on Modal Analysis
}

\author{
T. Plachý, M. Polák
}

Three studies of damage identification and localization based on methods using experimentally estimated modal characteristics are presented. The results of an experimental investigation of simple structural elements (three RC-beams and three RC-slabs) obtained in the laboratory are compared with the results obtained on a real structure (a composite bridge-a concrete deck supported by steel girders) in situ.

Keywords: modal analysis, natural mode, natural frequency, damage detection, MAC, COMAC, service life, fatigue.

\section{Introduction}

In practice, various kinds of damage to reinforced concrete structures can be found, such as mechanical damage due to cracking, corrosion of the reinforcement and deterioration of the concrete due to chemical actions from the environment. Undetected damage can lead to the failure of structural members or failure of the structure as the whole. Therefore monitoring of the degree of deterioration degree and damage detection of a structure at the earliest possible stage is very important. In many cases cracks are hidden, or damage is located inside the structure, and is only visible through changes in the overall properties. Current damage detection methods require that the vicinity of the damage is known a priori, and that the portion of the structure being inspected is readily accessible. The need for methods that can be applied to complex structures has led to the development of methods that examine changes in the modal characteristics of a structure.

Methods and procedures that use the results of an experimental modal analysis for estimating the degree of degradation of a structure can be verified on simple structural elements or complex structures (e.g. bridges [1] , [3]), when we know their damage state.

\section{Investigated structural elements}

Tests of structural elements of two types (Fig. 1) were carried out in the laboratories of the Faculty of Civil Engineering, CTU in Prague. The influence of increasing damage

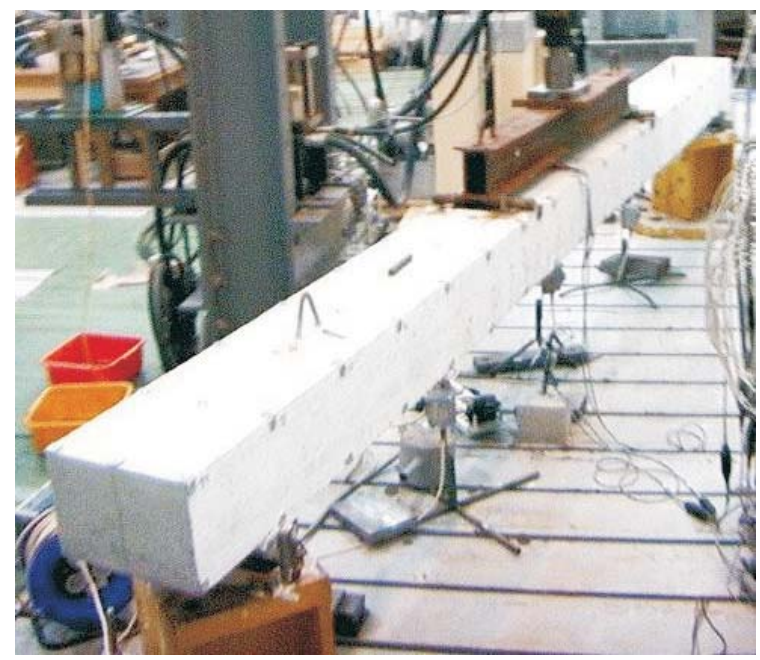

Fig. 1: View of the reinforced concrete beam and slab to reinforced concrete beams and slabs on their modal characteristics was monitored.

Three reinforced concrete beams with dimensions $4.5 \mathrm{~m} \times 0.3 \mathrm{~m} \times 0.2 \mathrm{~m}$ were prepared for the purposes of the test. The beam was placed on a cast steel bearing to achieve a good agreement with theoretical boundary conditions. It was a simply supported beam with a span length $4.0 \mathrm{~m}$ with cantilevered ends $0.25 \mathrm{~m}$ on both sides.

The state of deterioration of the beams performed by static loading and dynamic fatigue loading. The beams were tested in four-point bending to get a constant bending moment in the mid-section of the beam. Static loading was imposed in four steps (load by its self-weight, load effect equal to a theoretical limit of crack initiation, load to the first real cracking in the lower part of the beam, load to half of the ultimate moment). Then we continued with a dynamic fatigue load, induced by harmonic force. The amplitude of the dynamic load was chosen to achieve a stress range in the main reinforcement $\Delta \sigma=220 \mathrm{MPa}$, which would bring to an end of a the service life of the beam after 500000 cycles. In reality, the end of the service life of beam No. 1 came after 260000 cycles ( $52 \%$ of the theoretical lifetime). So for beams No. 2 and 3 the loading steps were divided into steps of about 65000 cycles. The end of the service life of beam No. 2 came after 220000 cycles (44\% of the theoretical lifetime), and for beam No. 3 after 255000 cycles $(51 \%$ of the theoretical lifetime).

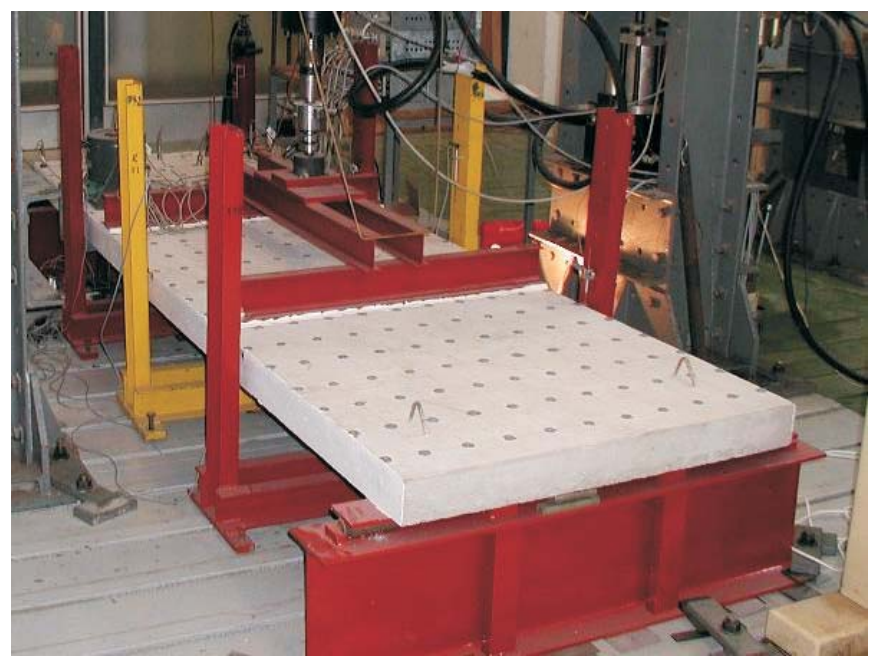



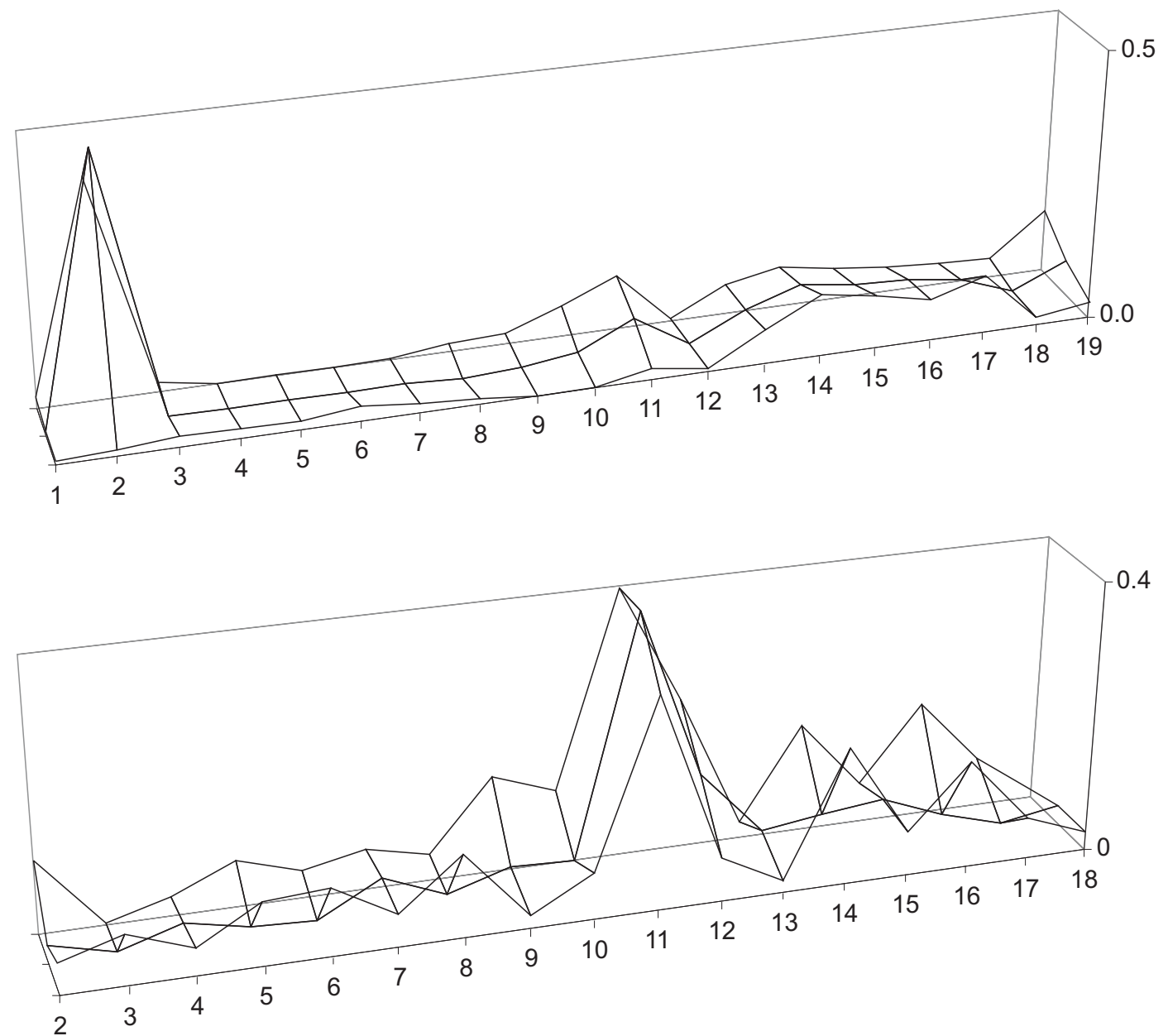

Fig. 2: Comparison of the dynamic behavior of beam No. 3 between the last but one and the last load step - functions (1-COMAC $\left.{ }_{(x)}\right)$ and $\operatorname{CAMOSUC}_{(3), x}$

Before the test and after each load step the dynamic response of the beam was measured with a separate test ar- rangement. For excitation of the beam during the experimental modal analysis, ESE 11076 electrodynamic shaker was

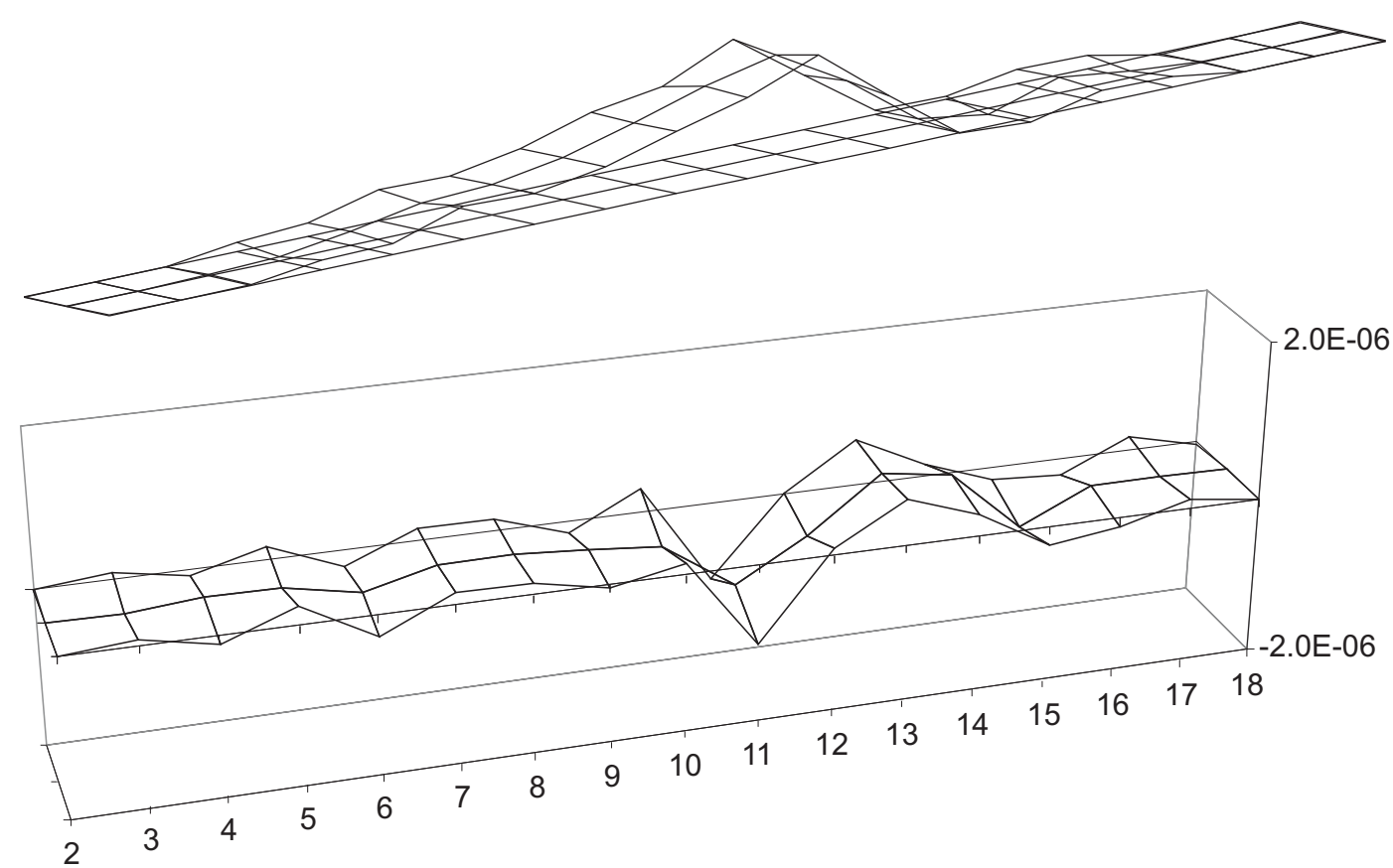

Fig. 3: Comparison of the dynamic behavior of beam No. 3 between the last but one and the last load step - change in the modal flexibility matrix $[\delta]$ and the second derivative of the change in the modal flexibility matrix $[\delta]$ 
used. The shaker produced a random driving force over the frequency range of 5 to $200 \mathrm{~Hz}$. The excitation force was measured indirectly by measuring the acceleration of the excitation mass. A B12/200 acceleration transducer HBM was placed on the excitation weight. The response of the elements to forcing by the exciter was measured by ten B12/200 HBM inductive acceleration transducers in a chosen net of points ( 5 points in each of 19 cross sections), on the upper face in the vertical direction and on the left side of the beam in the horizontal direction.

The shaker was placed centrally to the longitudinal axis of the beam. It covered two fifths of the beam span. The position of the point of excitation was designed to be able to excite the basic bending modes of the natural vibration of the beam. Values of the Frequency Response Function $H_{\mathrm{rS}}$ (if) were obtained as an average from ten measurements. The window length of the time signal processing was $16 \mathrm{~s}$, and the frequency range of the window was set to $200 \mathrm{~Hz}$.

The change in modal characteristics was monitored and confronted with the damage state of the beams. The modal characteristics of the beams, which were measured after each loading step, were compared with each other. The changes in natural frequencies $\Delta f_{(j)}$ were also computed. For the comparison of the natural modes, modal assurance coefficient $\mathrm{MAC}_{(j, j)}$, coordinate modal assurance criterion $\mathrm{COMAC}_{(p)}$, changes in mode surface curvature CAMOSUC $_{(j), x}$, changes in a modal flexibility matrix $\Delta[\delta]$ and the second derivative of the changes in the diagonal members of modal flexibility matrix $\Delta[\delta]^{\prime \prime}$ were used.

After the evaluation of the first test results of the beams, the second tests of the slabs were designed. Four reinforced concrete slabs with dimensions $3.2 \mathrm{~m} \times 1.0 \mathrm{~m} \times 0.1 \mathrm{~m}$ were

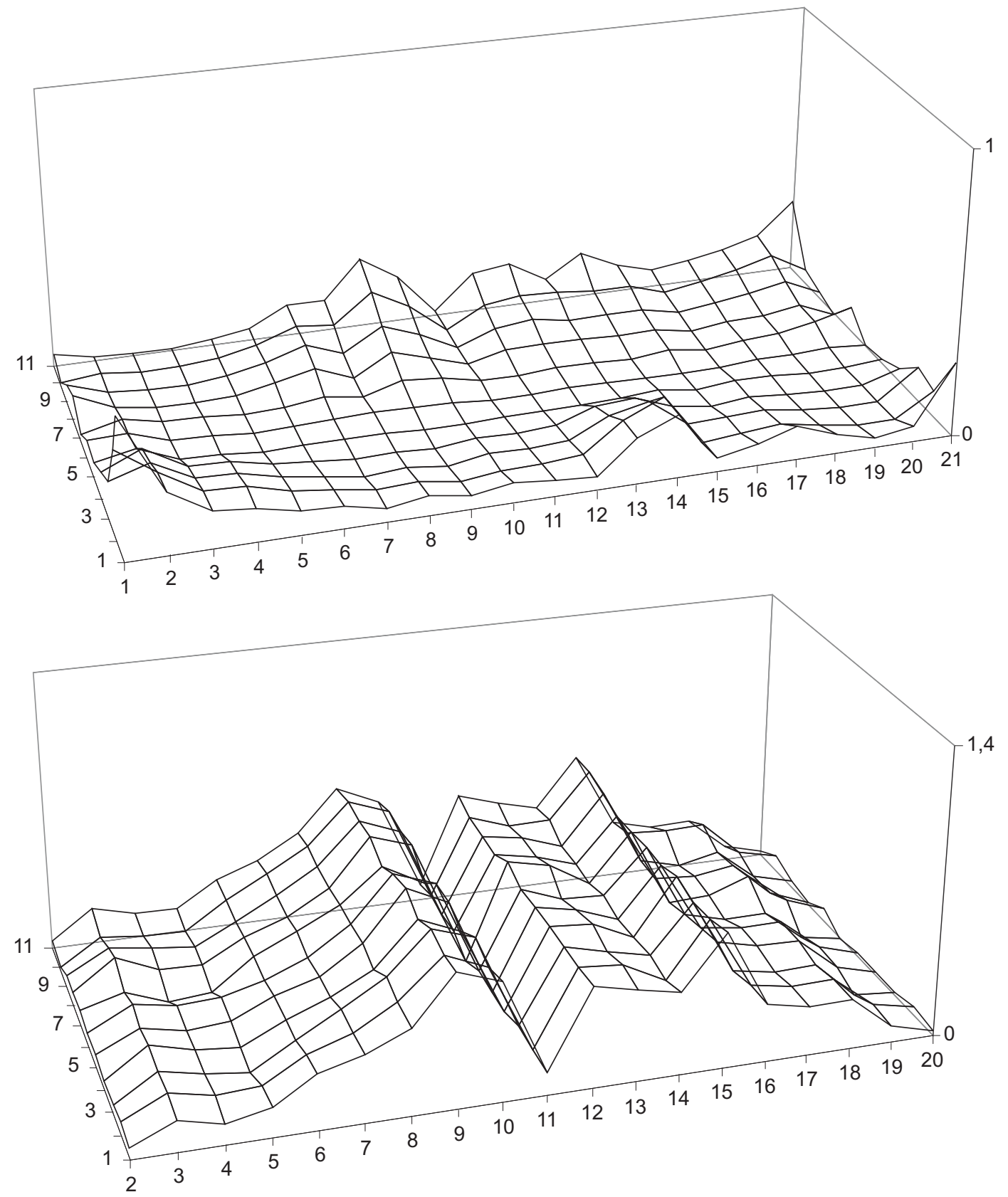

Fig. 4: Comparison of the dynamic behavior of the slab between the first and the last load step - functions (1-COMAC $(x)$ and CAMOSUC $_{(1), x}$ 

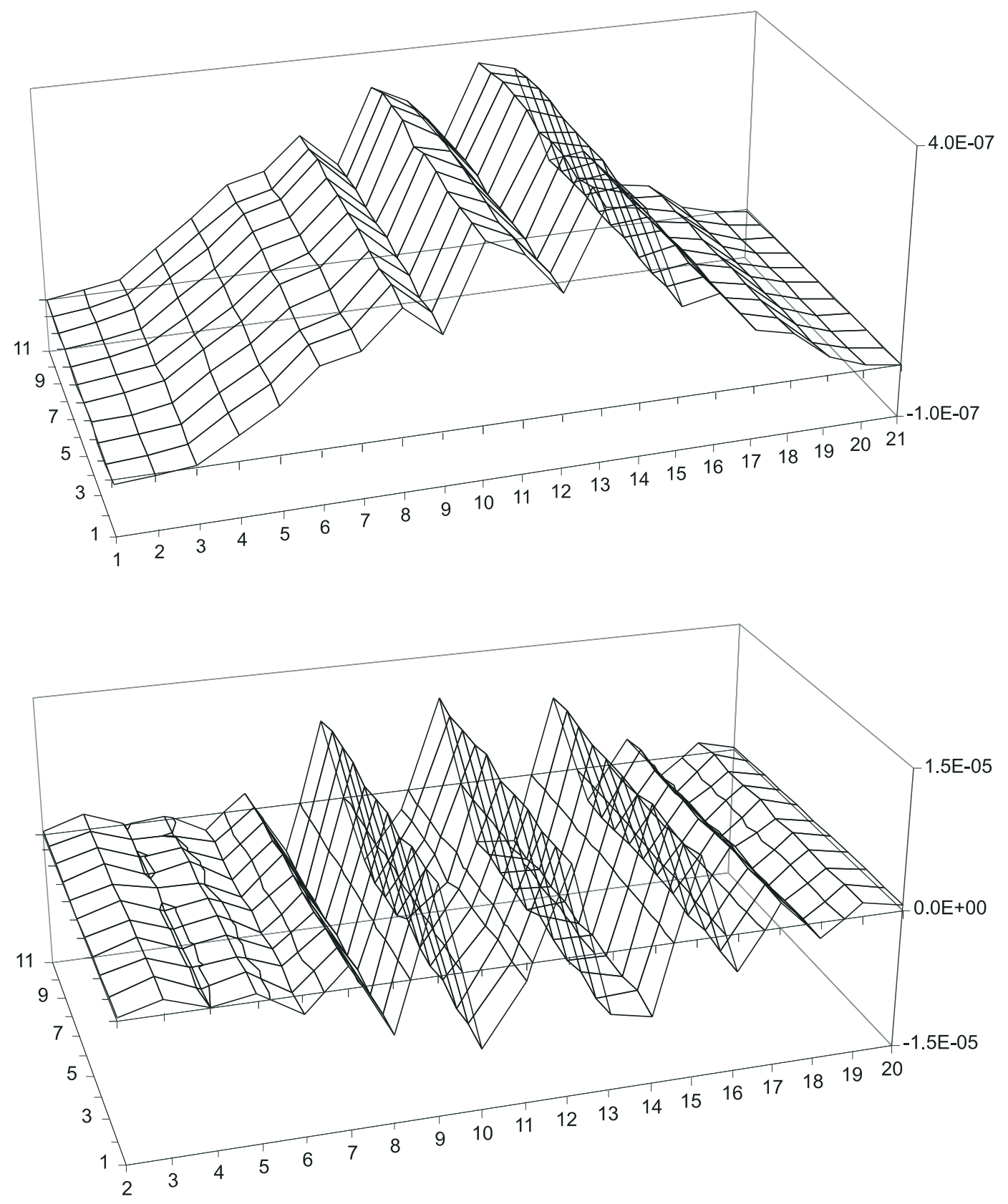

Fig. 5: Comparison of the dynamic behavior of the slab between the first and the last load step - change in the modal flexibility matrix [ $\delta$ ] and the second derivative of the change of the modal flexibility matrix $[\delta]$

made for the purposes of the test. The slabs were simply supported on two opposite sides with a span of $3.0 \mathrm{~m}$ and cantilevered ends $0.1 \mathrm{~m}$.

The slabs were also loaded by static and dynamic fatigue loading. Static loading was imposed in the same four steps as for the beams, but the steps for dynamic loading were different. In contrast to the beams, the end of the fatigue life of the first slab came after 1000000 cycles (200\% of the theoretical lifetime). Therefore, the fatigue load was performed in four steps (load to half of the theoretical lifetime - 250000 cycles, load to the theoretical lifetime - 500000 cycles, load to 750000 cycles, and load to the end of the real lifetime). Before the test and after each load step the dynamic response of the slab was measured with a separate test arrangement, as for the beams. The response of the slabs was measured only in the vertical direction in a chosen net of points (11 points in each of 21 cross sections) on the upper face. The change of modal characteristics was monitored and confronted with the damage state of the slabs, using the same coefficients as for the beams.

In order to lokalize of the cracks induced by the load increase during experimental and theoretical studies on structural elements the CAMOSUC $_{(j), x}$ (Fig. 2 and 4), the change of the modal flexibility matrix and especially the second derivative of the change of the diagonal members of the modal flexibility matrix seem to be most appropriate (Fig. 3 and 5).

To acquire reliable data to apprise the monitored structure based on $\mathrm{COMAC}_{(p)}$, the change of the modal flexibility matrix and the second derivative of the change of the diagonal members of the modal flexibility matrix it is very important to consider carefully the character and number of natural modes, that which are used in the computation. To determi- 
nate of $\operatorname{CAMOSUC}_{(j), x}$ it is most suitable to use the basic natural mode (the first vertical bending mode of the natural vibration), while for higher natural modes $\operatorname{CAMOSUC}_{(j), x}$ does not give as good results as for the first natural mode. For reliable analysis it is important to obtain reference data about the dynamic properties of the investigated structure in the undamaged virgin state, optimally before entering into operation.

\section{The bridge under investigation}

The bridge under investigation crosses highway D5 near the village of Vráž in the Czech Republic. The bearing structure of this composite bridge consists of four main steel I-girders and a reinforced concrete slab. It is a three-span continuous bridge with spans $11.7 \mathrm{~m}+35.1 \mathrm{~m}+11.0 \mathrm{~m}$. In March 2001 the bridge was damaged by a crash. A heavy vehicle (excavator) being ferried along the D5 crashed into its two main girders. The consequences of this crash was a permanent buckle of the main girder $(15 \mathrm{~cm}$ at the point of impact), and damage to the connection between the main girder and the crossbeam (Fig. 6).

An experimental modal analysis was carried out twice on this bridge - for the damaged state and for the state after reconstruction of the bridge. To vibrate the bridge, (Fig. 7) a TIRAVIB 5140 electrodynamic exciter was used. The driving force was white noise type in the range $0-20 \mathrm{~Hz}$, which was measured by S-35 LUKAS force transducers. The response of the bridge was measured only in the vertical direction in a chosen net of points (280 points - 28 cross sections and points in each cross section) on the upper face of the bridge by B12/200 HBM accelerometers. The data acquisition was performed by the 2550B Spectral Dynamics Vibration Control System with a Sun control computer. The STAR Spectral Dynamics program was used for modal characteristics evaluation.

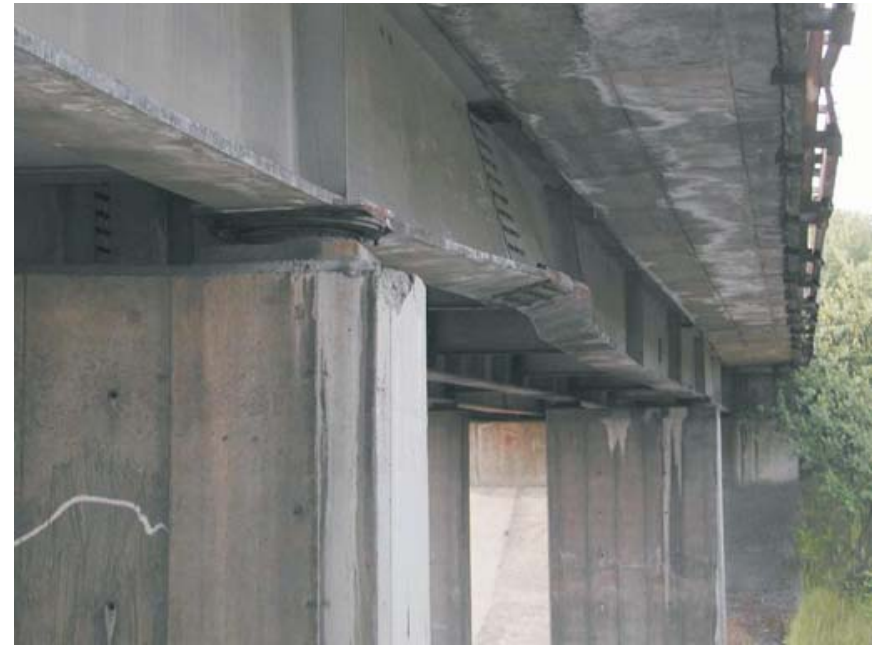

Fig. 6: View of the damaged main girder of the bridge

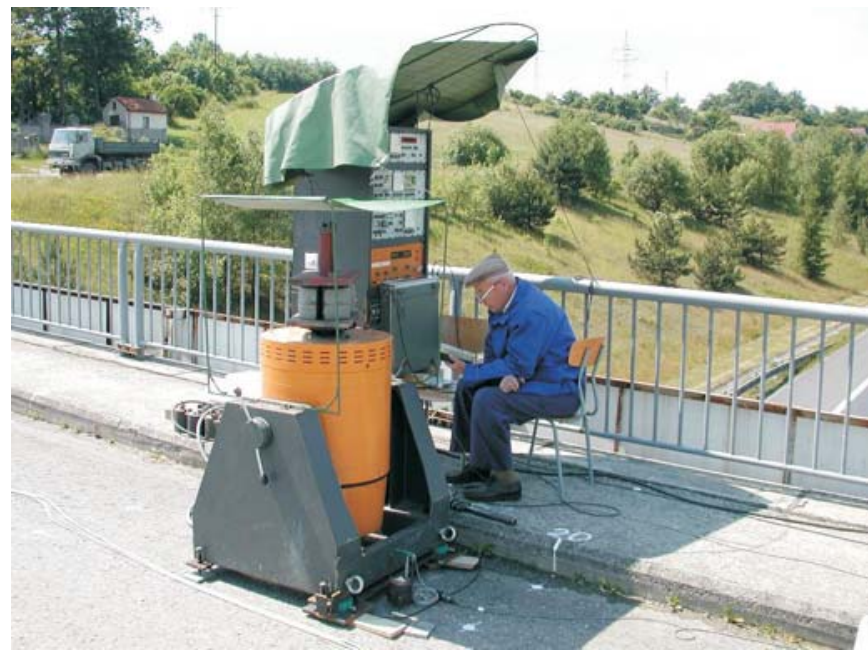

Fig. 7: The TIRAVIB 5140 electrodynamic exciter and its placement on the bridge

Table 1: The bridge across the highway D5 near Vráž - comparison of natural modes from the first and from the second stage of the experimental investigation of the bridge using MAC

\begin{tabular}{|c|c|c|c|c|c|c|c|c|c|c|c|}
\hline \multirow{2}{*}{$\begin{array}{c}\text { State after } \\
\text { reconstruction } \\
\text { the 2nd stage }\end{array}$} & \multicolumn{10}{|c|}{ Damaged state - the 1st stage } \\
\cline { 2 - 14 } & 1 & 2 & 3 & 4 & 5 & 6 & 7 & 8 & 8 & 10 & 11 \\
\hline 1 & $\mathbf{0 . 9 3 7}$ & 0.205 & 0.038 & 0.018 & 0.000 & 0.010 & 0.000 & 0.004 & 0.011 & 0.003 & 0.004 \\
\hline 2 & 0.005 & $\mathbf{0 . 6 7 4}$ & 0.045 & 0.054 & 0.003 & 0.001 & 0.000 & 0.007 & 0.002 & 0.001 & 0.020 \\
\hline 3 & 0.084 & 0.022 & $\mathbf{0 . 6 1 8}$ & $\mathbf{0 . 3 4 5}$ & 0.027 & 0.063 & 0.001 & 0.020 & 0.087 & 0.012 & 0.000 \\
\hline 4 & 0.001 & 0.026 & $\underline{\mathbf{0 . 3 7 8}}$ & $\mathbf{0 . 3 3 8}$ & 0.017 & 0.024 & 0.001 & 0.014 & 0.013 & 0.003 & 0.002 \\
\hline 5 & 0.008 & 0.001 & 0.259 & 0.110 & 0.241 & 0.050 & 0.001 & 0.061 & 0.049 & 0.031 & 0.001 \\
\hline 6 & 0.000 & 0.001 & 0.091 & 0.050 & $\mathbf{0 . 9 2 8}$ & 0.062 & 0.000 & 0.019 & 0.017 & 0.002 & 0.003 \\
\hline 7 & 0.004 & 0.001 & 0.000 & 0.019 & 0.014 & 0.121 & 0.099 & 0.113 & 0.005 & 0.000 & 0.008 \\
\hline 8 & 0.000 & 0.002 & 0.000 & 0.003 & 0.001 & 0.015 & $\mathbf{0 . 5 7 6}$ & 0.001 & 0.004 & 0.002 & 0.000 \\
\hline 9 & 0.009 & 0.000 & 0.014 & 0.013 & 0.001 & $\mathbf{0 . 3 3 0}$ & 0.194 & 0.017 & 0.032 & 0.001 & 0.009 \\
\hline 10 & 0.004 & 0.001 & 0.042 & 0.113 & 0.031 & 0.039 & 0.254 & $\mathbf{0 . 7 7 2}$ & 0.181 & 0.006 & 0.173 \\
\hline 11 & 0.010 & 0.001 & 0.023 & 0.005 & 0.004 & 0.011 & 0.014 & 0.135 & 0.272 & 0.006 & 0.011 \\
\hline 12 & 0.023 & 0.000 & 0.047 & 0.000 & 0.000 & 0.261 & 0.002 & 0.033 & 0.022 & $\underline{\mathbf{0 . 3 2 6}}$ & 0.035 \\
\hline
\end{tabular}


Frequency Response Function - point 112

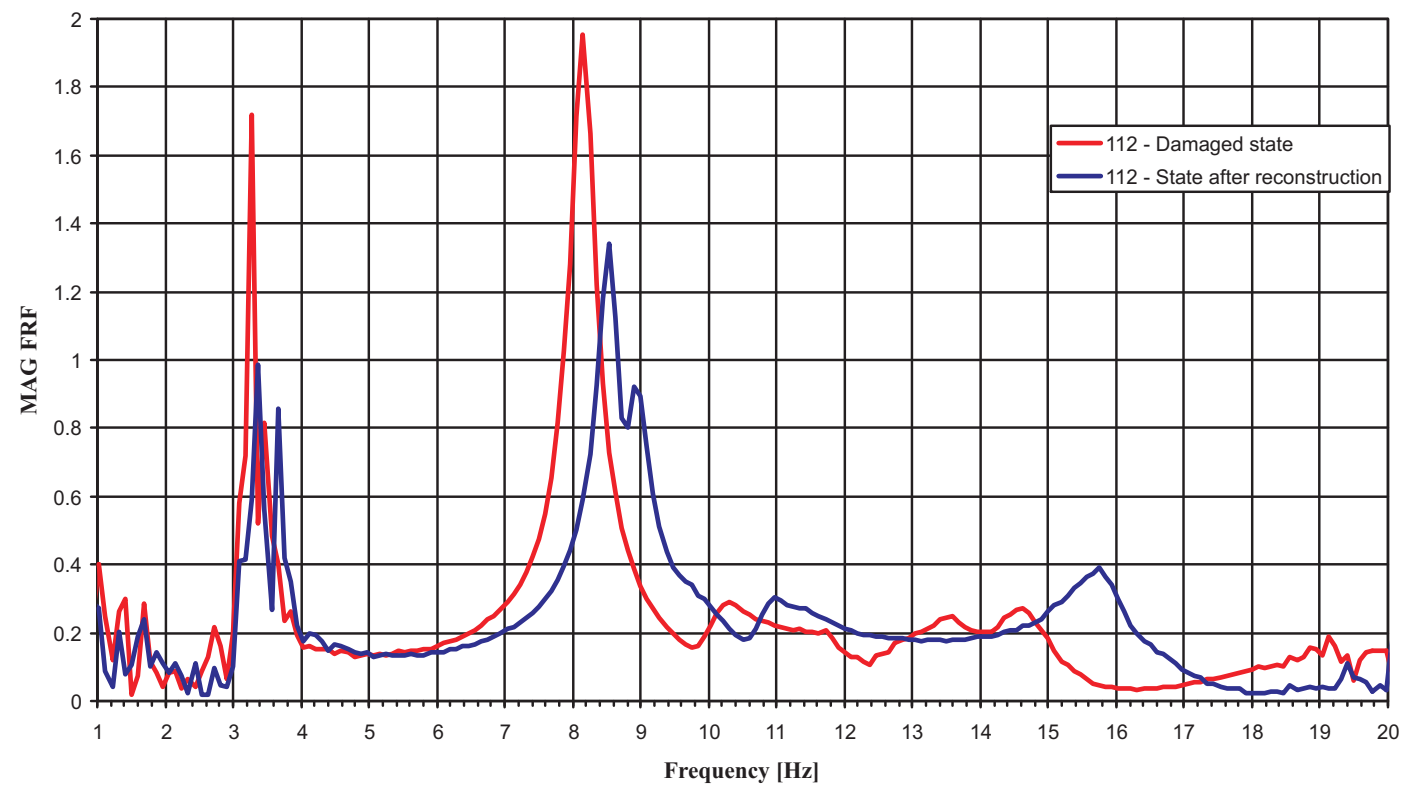

Frequency Response Function - point 118

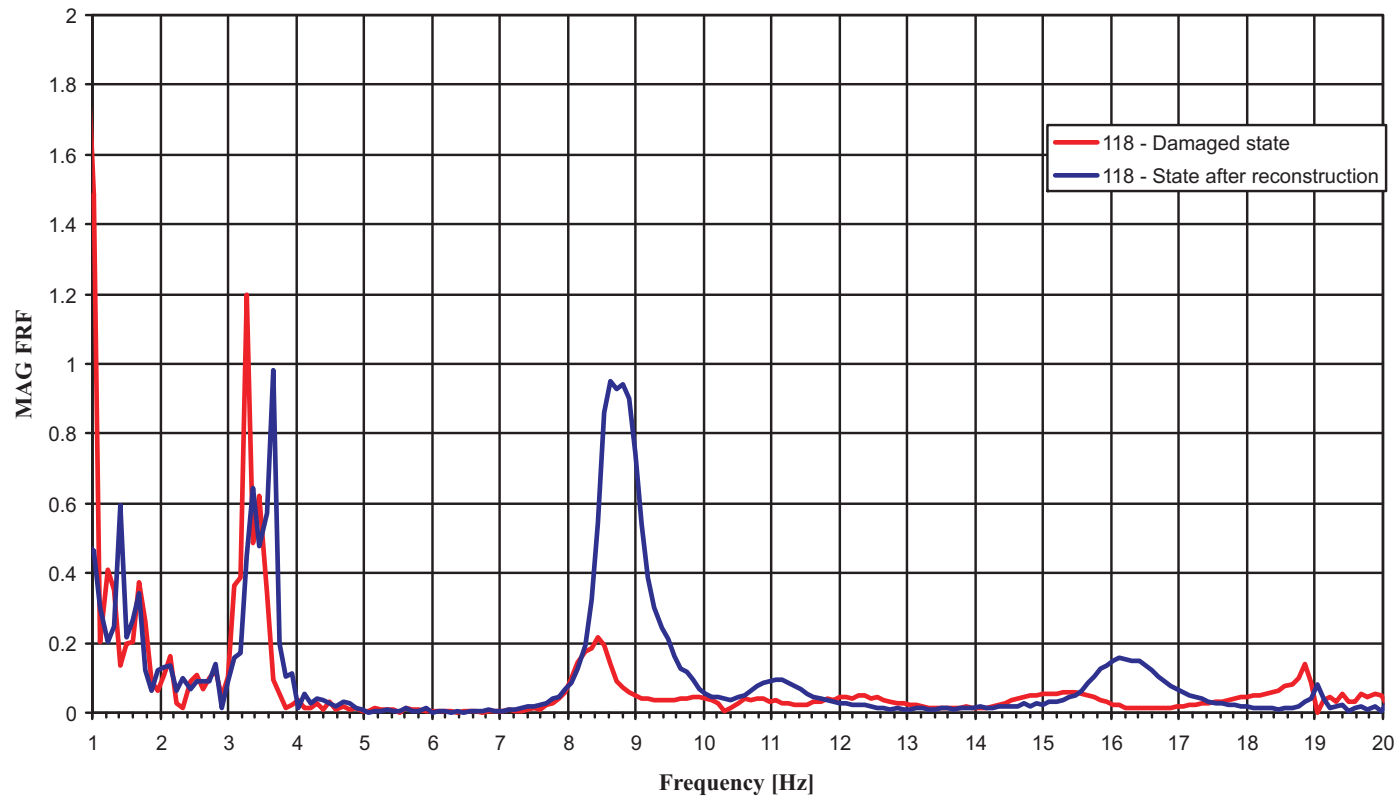

Fig. 8: Comparison of the Frequency Response Functions measured at points 112 (the point at upon the middle of the damaged part of the main girder) and 118 (the point in the same cross section on the exterior undamaged main girder) in the damaged state and in the state after reconstruction

Eleven natural frequencies, modal shapes and damping frequencies were evaluated after the first stage (the damaged state) of experimental bridge monitoring, and twelve natural frequencies, modal shapes and damping frequencies were evaluated after the second stage (the state after reconstruction) of experimental bridge monitoring.

Just from a visual comparison of the characters of the natural modes evaluated in the damaged and repaired states (Fig. 10-13) and the measured frequency response functions
(Fig. 8), it is clear that the changes resulting from the reconstruction of the damaged girder are substantial. For this reason, the natural modes of the two verified states of the bridge were compared with each other using the $\mathrm{MAC}_{(i, j)}$ assurance criterion (Tab. 1, Fig. 9). Table 1 shows are highlighted values of $\mathrm{MAC}_{(i, j)}$ for the modes that have very similar characters. A visual comparison of these modes as shown in Fig. 10-13.

Values of $\mathrm{MAC}_{(i, j)}$, that show less correlating modes are highlighted by underlined bold numbers. Natural modes 


\section{Comparison of natural modes of vibration of the bridge near Vráž - MAC}

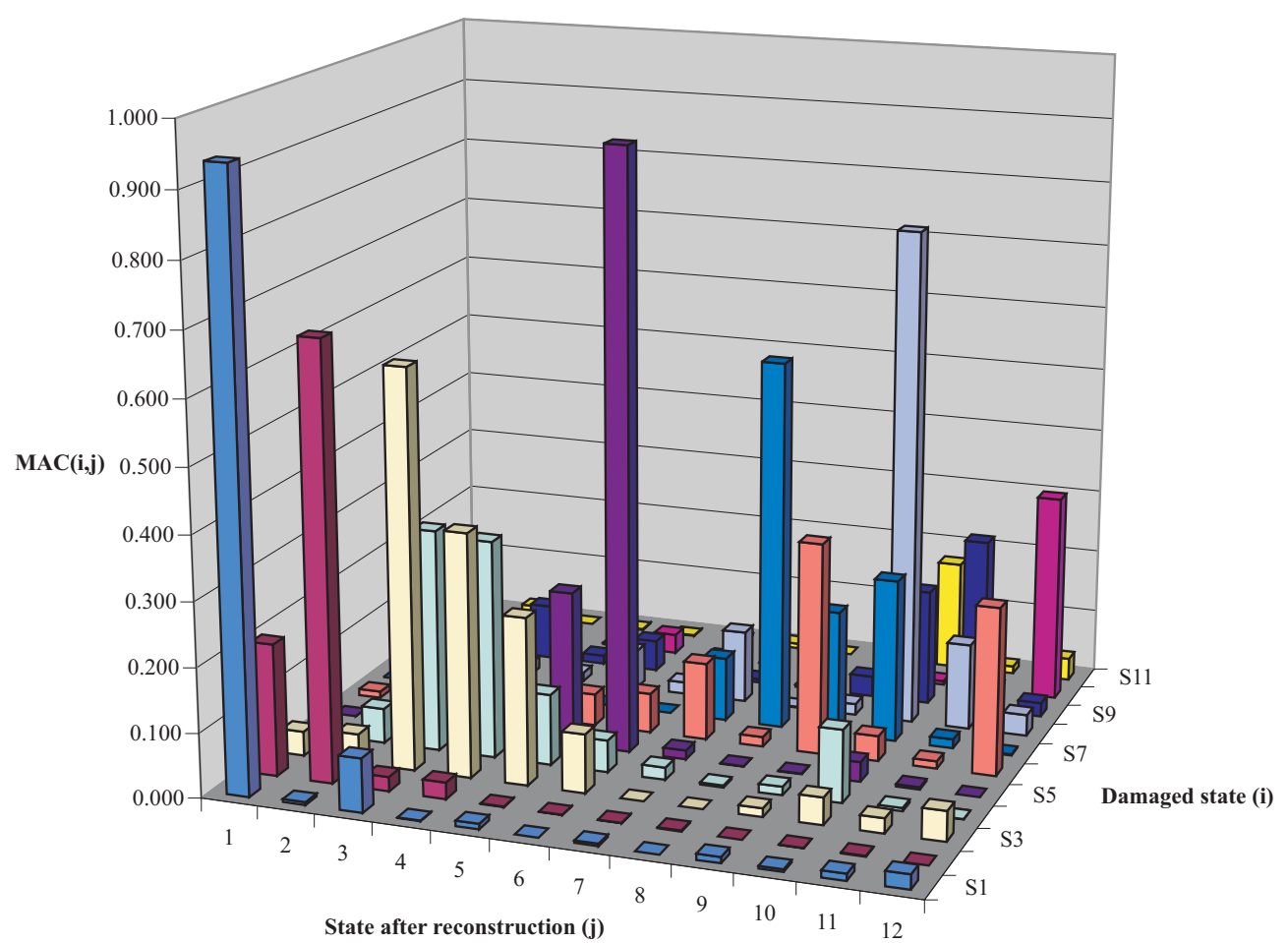

Fig. 9: The bridge across highway D5 near Vráž - comparison of natural modes from the $1^{\text {st }}$ and from the $2^{\text {nd }}$ stage of the experimental investigation of the bridge, using MAC

Table 2: The bridge across highway D5 near Vráž - the change of natural frequencies $\Delta f_{(j)}$ and damping frequencies $\Delta f_{b(j)}$ caused by reconstruction of the main girder

\begin{tabular}{|c|c|c|c|c|c|c|c|c|}
\hline \multicolumn{9}{|c|}{ Natural modes with similar character of vibration } \\
\hline \multirow{2}{*}{\multicolumn{3}{|c|}{$\begin{array}{c}\text { Damaged state } \\
\text { June } 2001\end{array}$}} & \multirow{2}{*}{\multicolumn{3}{|c|}{$\begin{array}{c}\text { State after reconstruction } \\
\text { October } 2001\end{array}$}} & \multicolumn{3}{|c|}{ Characteristics of change } \\
\hline & & & & & & \multirow{2}{*}{$\begin{array}{c}\text { Natural } \\
\text { frequencies } \Delta f_{(j)} \\
{[\%]}\end{array}$} & \multirow{2}{*}{$\begin{array}{c}\text { Damping } \\
\text { frequencies } \Delta f_{b(j)} \\
{[\%]}\end{array}$} & \multirow{2}{*}{$\begin{array}{c}\text { Natural } \\
\text { modes } \\
\text { MAC }\end{array}$} \\
\hline $\begin{array}{l}\text { No. } \\
(j)\end{array}$ & $\begin{array}{c}f_{(j)} \\
{[\mathrm{Hz}]}\end{array}$ & $\begin{array}{l}f_{b(j)} \\
{[\mathrm{Hz}]}\end{array}$ & $\begin{array}{c}\text { No. } \\
\text { (i) }\end{array}$ & $\begin{array}{c}f_{(j)} \\
{[\mathrm{Hz}]}\end{array}$ & $\begin{array}{l}f_{b(j)} \\
{[\mathrm{Hz}]}\end{array}$ & & & \\
\hline$(1)$ & 3.26 & 0.093 & $(1)$ & 3.38 & 0.051 & 3.7 & -45.3 & 0.937 \\
\hline$(2)$ & 3.41 & 0.135 & $(2)$ & 3.65 & 0.114 & 7.0 & -15.3 & 0.674 \\
\hline$(3)$ & 8.16 & 0.161 & (3) & 8.54 & 0.147 & 4.7 & -8.5 & 0.618 \\
\hline$(5)$ & 10.21 & 0.421 & (6) & 10.86 & 0.316 & 6.4 & -24.9 & 0.928 \\
\hline (7) & 13.74 & 0.368 & (8) & 14.18 & 0.402 & 3.2 & 9.4 & 0.576 \\
\hline (8) & 14.72 & 0.458 & $(10)$ & 15.89 & 0.461 & 7.9 & 0.7 & 0.772 \\
\hline \multicolumn{9}{|c|}{ Natural modes with lesser correlation } \\
\hline (3) & 8.16 & 0.161 & (4) & 8.95 & 0.199 & 9.7 & 24.0 & 0.378 \\
\hline$(4)$ & 8.42 & 0.171 & (3) & 8.54 & 0.147 & 1.4 & -13.8 & 0.345 \\
\hline (4) & 8.42 & 0.171 & $(4)$ & 8.95 & 0.199 & 6.3 & 16.8 & 0.338 \\
\hline$(6)$ & 12.01 & 0.475 & $(9)$ & 15.17 & 1.060 & 26.3 & 123.4 & 0.330 \\
\hline$(10)$ & 17.59 & 1.280 & $(12)$ & 19.25 & 0.329 & 9.4 & -74.3 & 0.326 \\
\hline \multicolumn{9}{|c|}{ Less correlating modes } \\
\hline (3) & 8.16 & 0.161 & (5) & 9.58 & 0.741 & 17.4 & 361.1 & 0.259 \\
\hline (6) & 12.01 & 0.475 & $(7)$ & 11.39 & 0.400 & -5.2 & -96.7 & 0.121 \\
\hline (9) & 15.58 & 0.768 & $(11)$ & 16.58 & 0.578 & 6.4 & -96.3 & 0.272 \\
\hline (11) & 19.14 & 0.217 & (10) & 15.89 & 0.461 & -17.0 & -97.6 & 0.173 \\
\hline
\end{tabular}




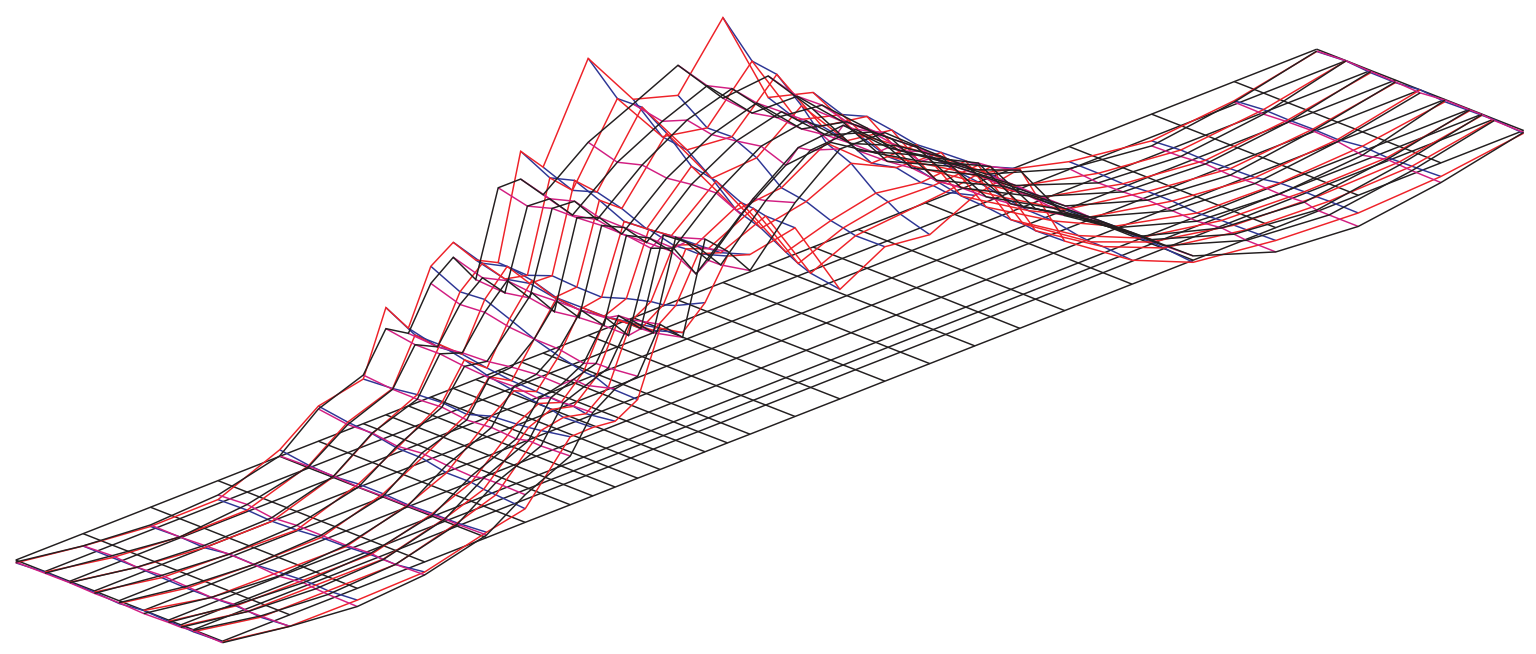

Fig. 10: Visual comparison of the real parts of the natural modes for the state after reconstruction (the first natural mode) and for the damaged state (the first natural mode) $-\mathrm{MAC}_{(1,1)}=0.937$

No. 5, 7 and 11 for the state after reconstruction, and natural modes No. 9 and 11 for the damaged state, correlate less strongly with all of the modes for the other state.

The changed size of the natural frequencies $\Delta f_{(j)}$ and damping frequencies $\Delta f_{b(j)}$ caused by reconstruction of the damaged girder are listed in Table 2. Compared pairs of $f_{(j)}$ and $f_{b(j)}$ were allocated to each other based on the natural mode correlation specified by $\mathrm{MAC}_{(i, j)}$ (Table 1). The comparison was done separately for the natural modes with similar character of vibration, for the natural modes with less correlation, and for the least correlating modes.

Not only $\mathrm{MAC}_{(i, j)}$ was used for the comparison of natural modes but also $\mathrm{COMAC}_{(p)}$ (Fig. 14), the change of the curvature of natural modes CAMOSUC $(j), p$ (Fig. 15-18), the change of the modal flexibility matrix $[\delta]$ and the second derivative of the change of the diagonal members of the modal flexibility matrix $\Delta \delta^{\prime \prime}$ (Fig. 19 and 20) were used.

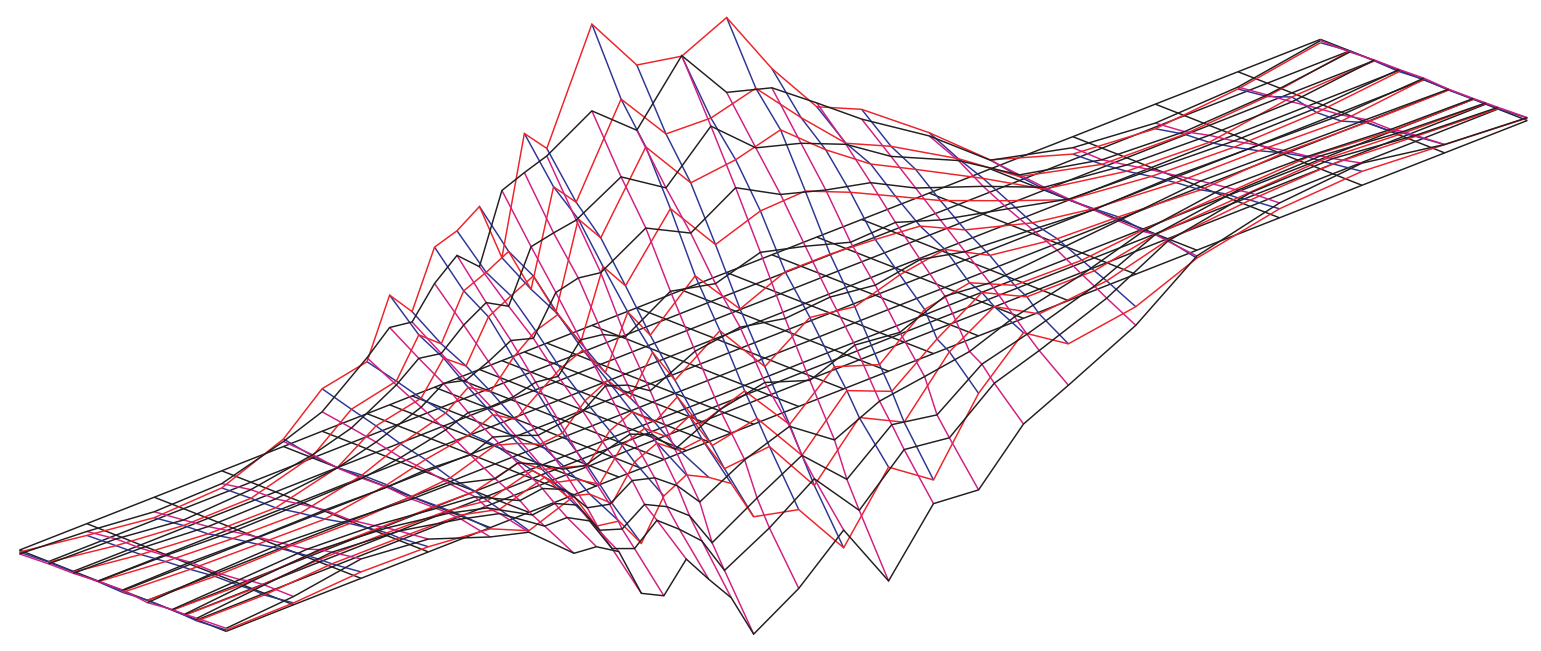

Fig. 11: Visual comparison of the real parts of the natural modes for the state after reconstruction (the second natural mode) and for the damaged state (second natural mode) $-\mathrm{MAC}_{(2,2)}=0.674$ 

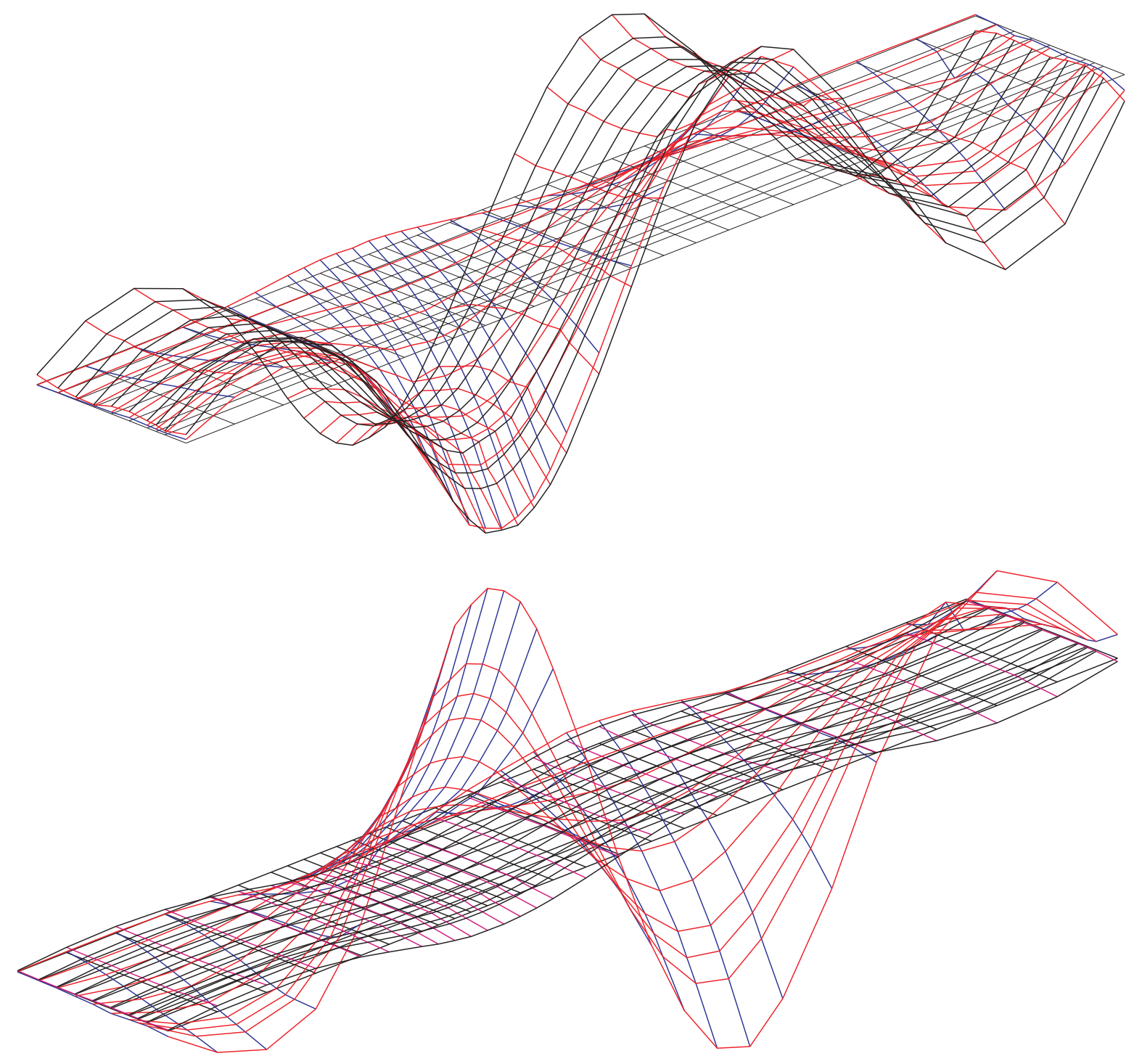

Fig. 12: Visual comparison of the real parts of the natural modes for the state after reconstruction (third natural mode) and for the damaged state (third natural mode) $-\mathrm{MAC}_{(3,3)}=0.618$. (above - comparison in the section of the damaged girder, below - comparison in the section of the undamaged girder.)

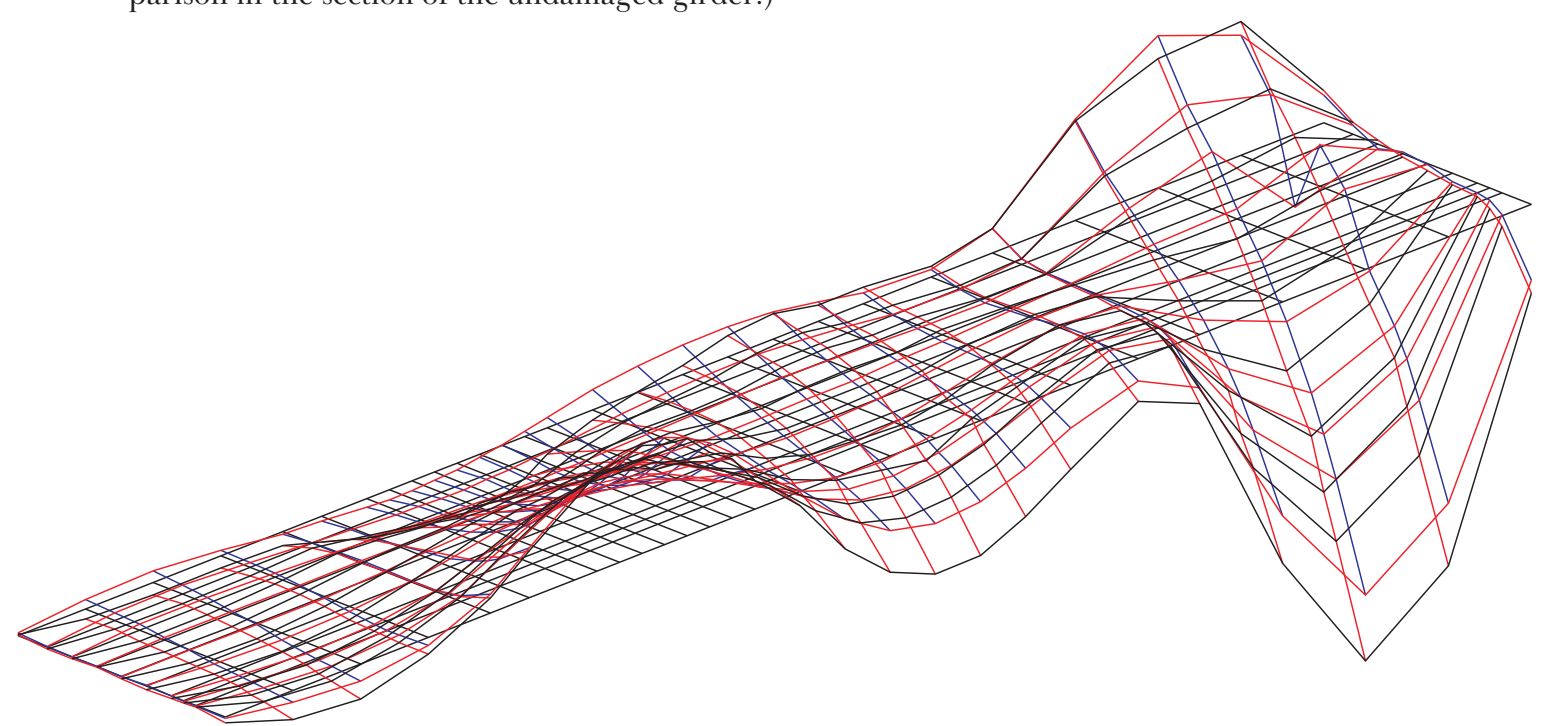

Fig. 13: Visual comparison of the real parts of the natural modes for the state after reconstruction (sixth natural mode) and for the damaged state (fifth natural mode) $-\mathrm{MAC}_{(6,5)}=0.928$ 


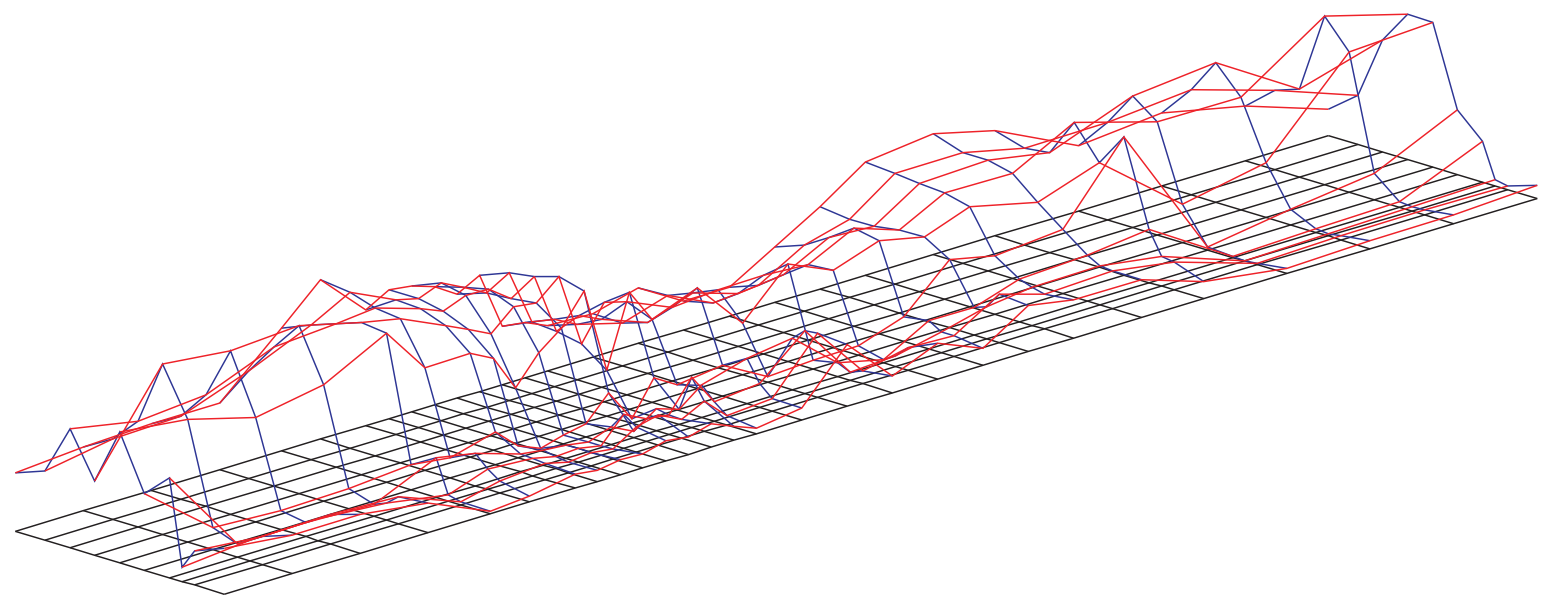

Fig. 14: The change in the dynamic behavior of the bridge (damaged state - state after reconstruction) described by function (1-COMAC), used natural modes No. 1, 2, 3, 5, 7, 8 (damaged state) and 1, 2, 3, 6, 8, 10 (state after reconstruction), max. value shown in the figure is 0.887 (i.e. $\mathrm{COMAC}_{(128)}=0.113$ ) at point 128

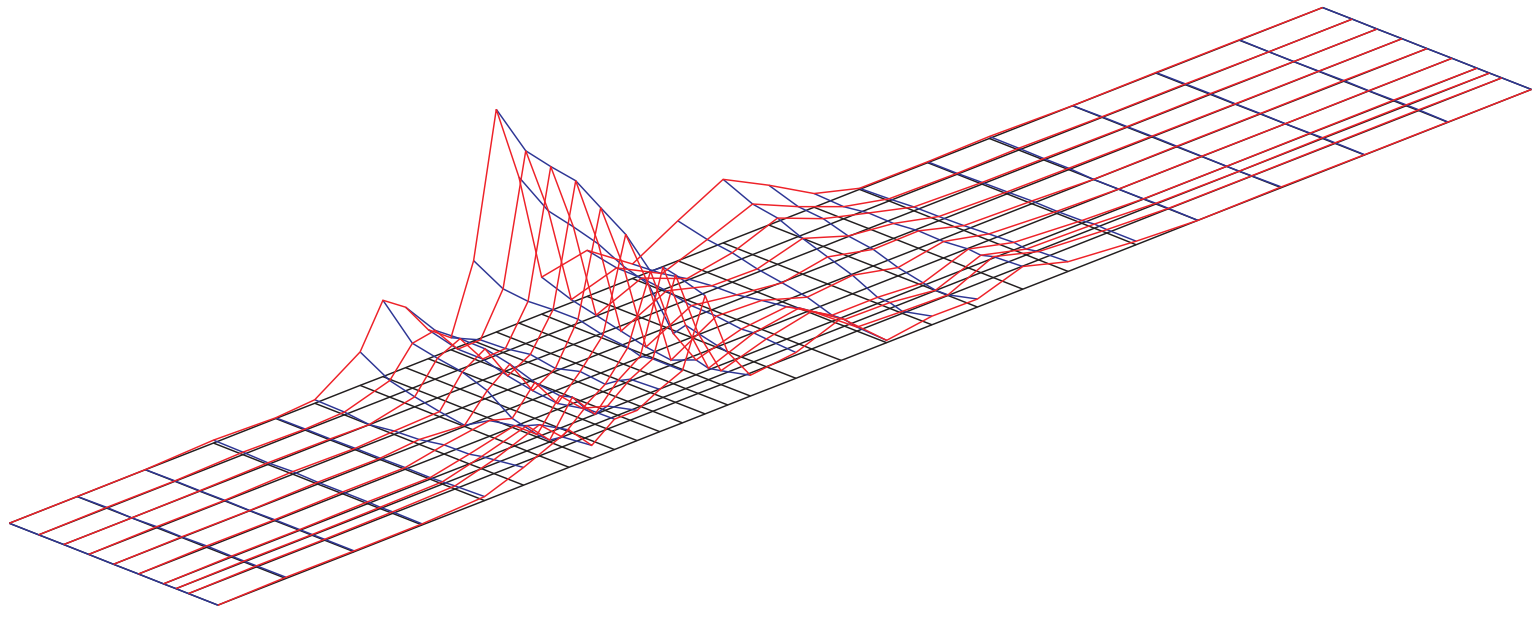

Fig. 15: The change in the dynamic behavior of the bridge (damaged state - state after reconstruction) described by the change of the curvature of the first natural mode $\mathrm{CAMOSUC}_{(1)}$ calculated in the longitudinal direction of the bridge

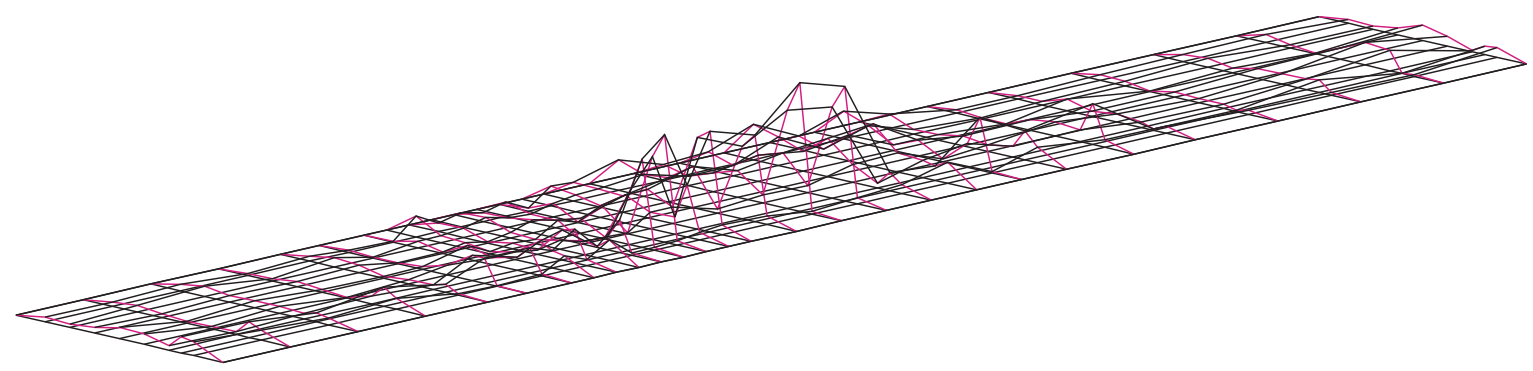

Fig. 16: The change of the dynamic behavior of the bridge (damaged state - state after reconstruction) described by the change of the curvature of the first natural mode $\mathrm{CAMOSUC}_{(1)}$ calculated in the transversal direction of the bridge 


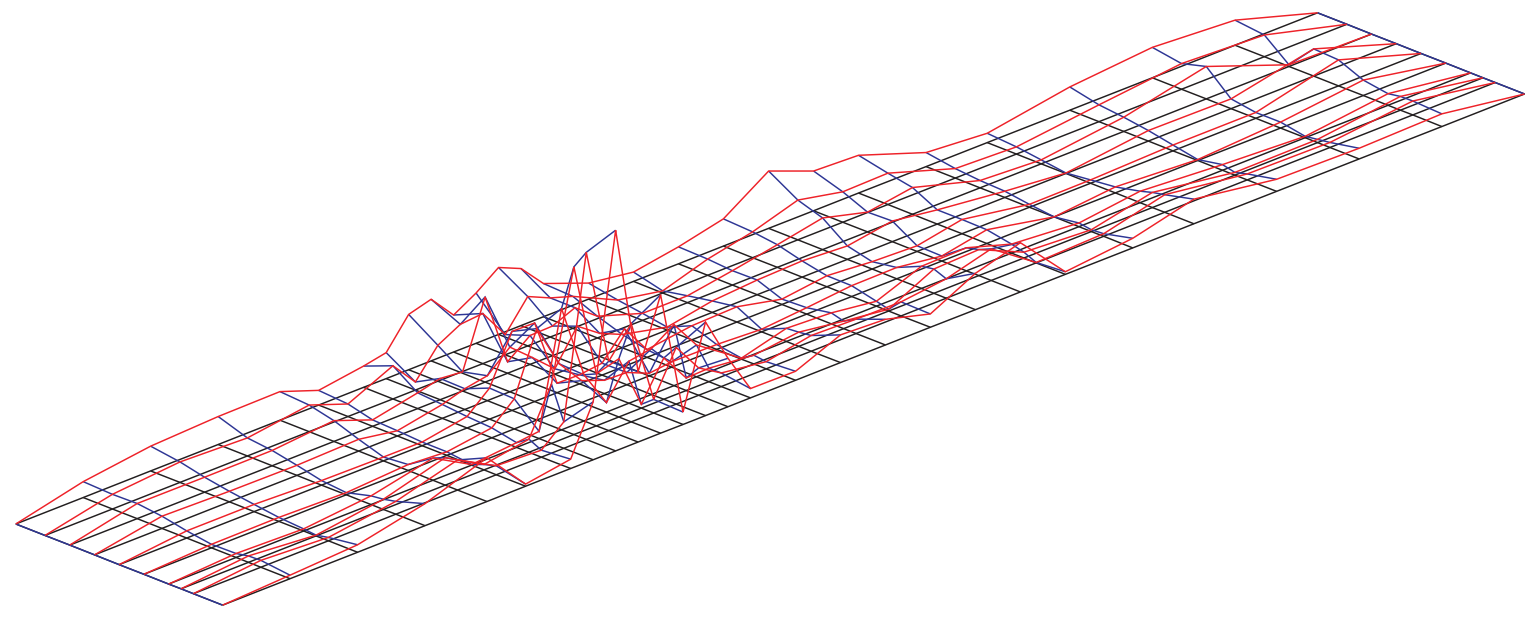

Fig. 17: The change of the dynamic behavior of the bridge (damaged state - state after reconstruction) described by the change of the curvature of the third natural mode $\operatorname{CAMOSUC}_{(3)}$ calculated in the longitudinal direction of the bridge

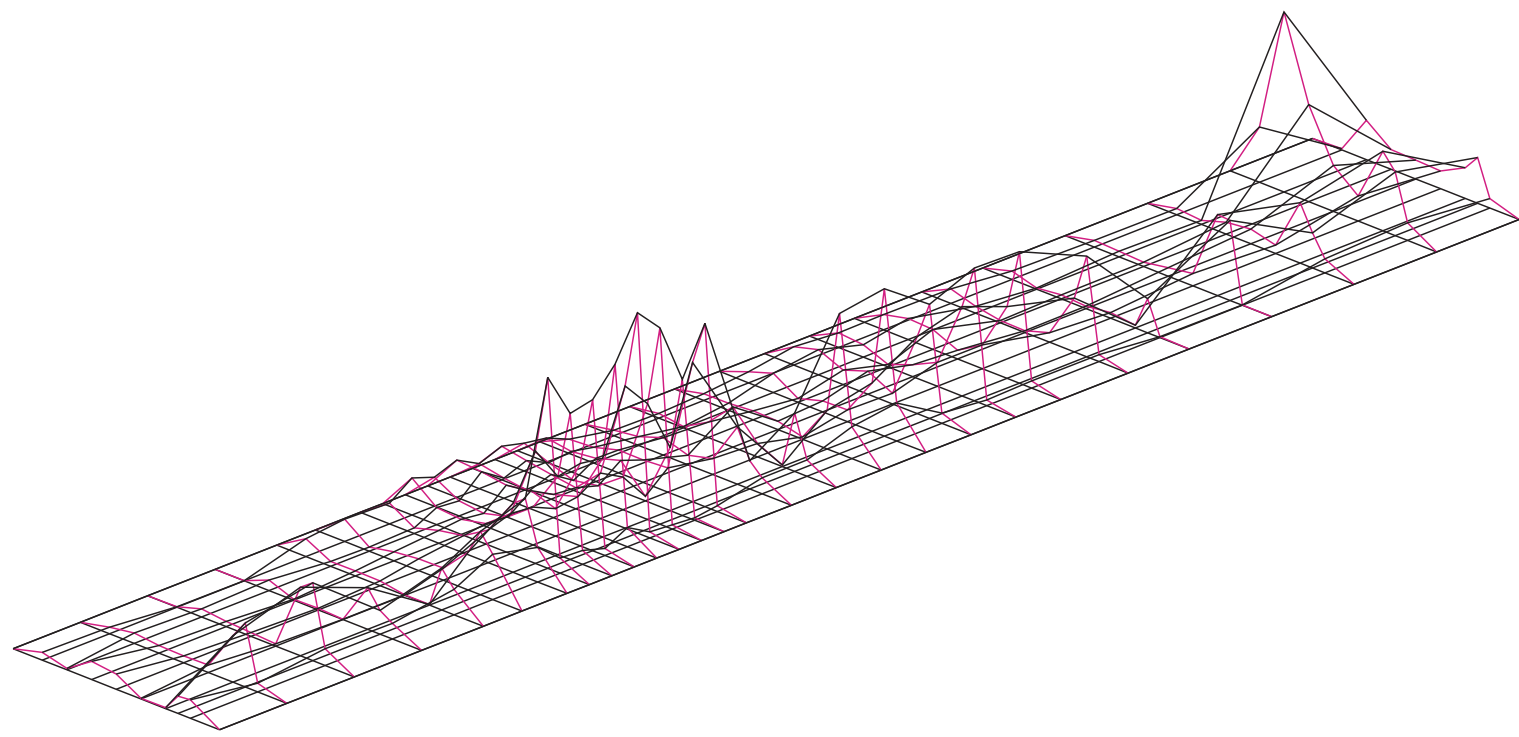

Fig. 18: The change in the dynamic behavior of the bridge (damaged state - state after reconstruction) described by the change of the curvature of the third natural mode $\mathrm{CAMOSUC}_{(3)}$ calculated in the transversal direction of the bridge

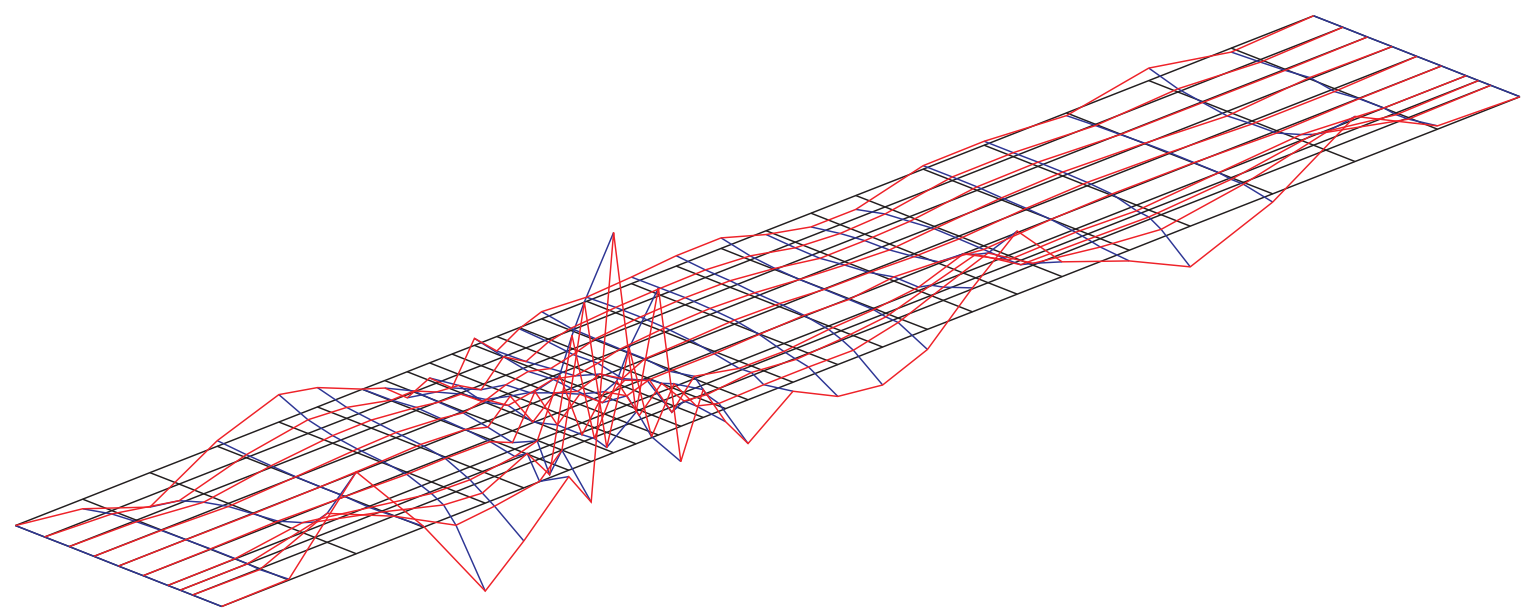

Fig. 19: The change in the dynamic behavior of the bridge (damaged state - state after reconstruction) described by the second derivative of the diagonal members of the modal flexibility matrix $\Delta \delta^{\prime \prime}$ computed in the longitudinal direction of the bridge, used natural modes No. 3, 5, 7, 8 (damaged state) and 3, 6, 8, 10 (state after reconstruction) 


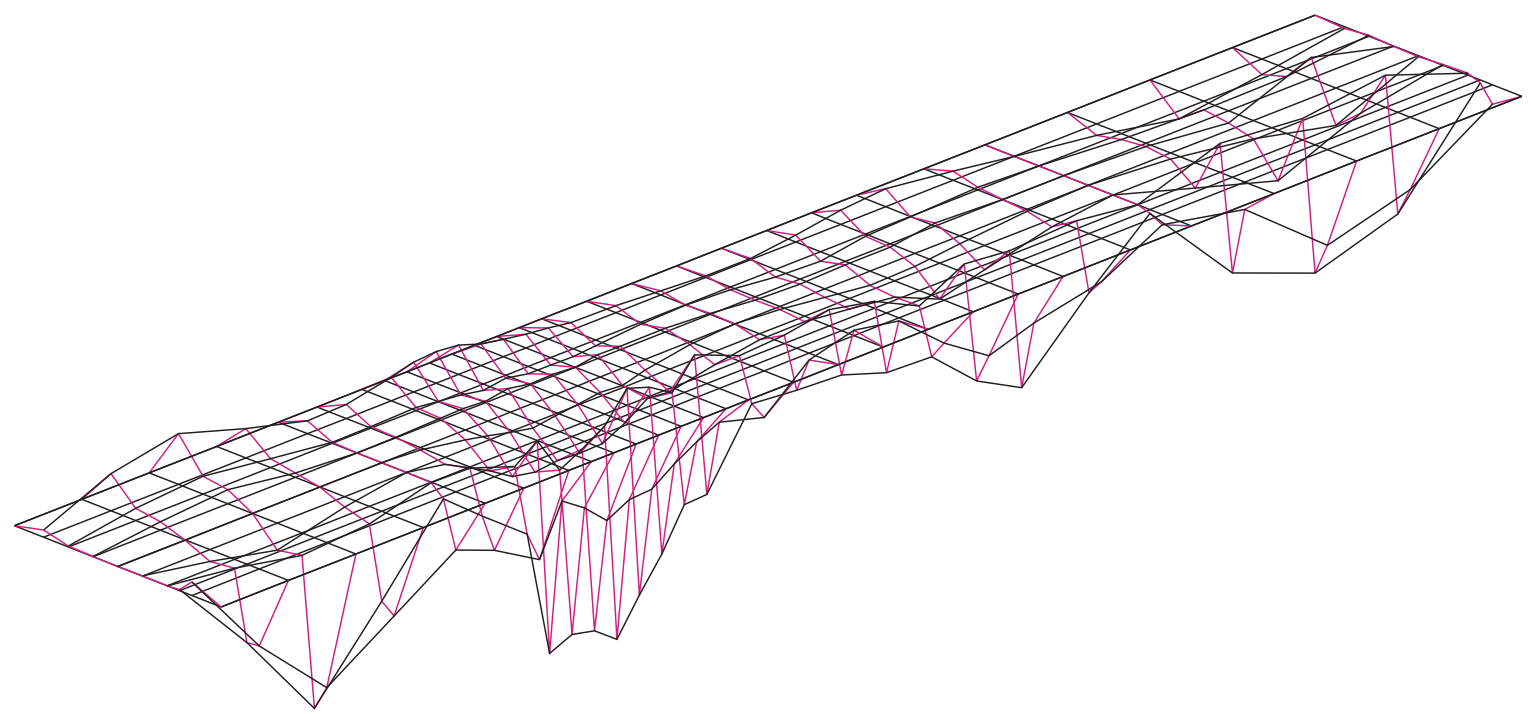

Fig. 20: The change in the dynamic behavior of the bridge (damaged state - state after reconstruction) described by the second derivative of the diagonal members of the modal flexibility matrix $\Delta \delta^{\prime \prime}$ computed in the transversal direction of the bridge, used natural modes No. 3, 5, 7, 8 (damaged state) and 3, 6, 8, 10 (state after reconstruction)

\section{Conclusion}

The evaluated results show that damage to the main girder and its reconstruction significantly influenced the dynamic behavior of the investigated bridge across highway D5 near Vráž. The ascertained changes of modal characteristics are significant, and confirm the improvement of the structural state of the bridge after reconstruction of the main girder.

The change of the mode shapes was so great that coefficient MAC had to be used to find corresponding modes for comparison. For damage detection and localization on this bridge the use of natural frequency changes, changes of mode surface curvature CAMOSUC $_{(j), x}$, changes of modal flexibility matrix $\Delta[\delta]$ and the second derivative of changes of the diagonal members of a modal flexibility matrix $\Delta[\delta]^{\prime \prime}$ proved to be appropriate.

Unlike the results obtained on simple structural elements, it seems that for damage localization on complex structures using CAMOSUC $_{(j), x}$ not only the first natural mode but also the higher modes can be used. In particular it is suitable to use a combination of the values of CAMOSUC $(j), x$ computed in the longitudinal and transversal direction of the bridge.

This investigation of methods for damage detection and localization was supported by MSMT of the Czech Republic as a part of project CEZ: J04/98: 210000030.

\section{References}

[1] Brincker R., Andersen P., Cantieni R.: "Identification and Level I Damage Detection of the Z24 Highway Bridge." Experimental Techniques, Vol. 25 (2001), No. 6, p. 51-57.

[2] Farrar C. R., Jauregui D. A.: "Comparative Study of Damage Identification Algorithms Applied to a Bridge: I
Experiment." Smart Materials and Structures, Vol. 7 (1998), p. 704-719.

[3] Feltrin G., Motavalli M.: "Vibration-based Damage Detection on a Highway Bridge." Proc. of the $1^{\text {st }}$ Int. Conf. on Bridge Maintenance, Safety and Management, 2002.

[4] Frýba L., Pirner M., Urushadze S.: "Localization of Damages in Concrete Structures." Proc. of the Int. Conf. Computational Methods and Experimental Measurements X, 2001.

[5] Plachý T.: "Dynamic Study of a Reinforced Concrete Beam Damaged by Cracks.” PhD thesis, CTU in Prague, FCE, Prague, 2003.

[6] Plachý T., Polák M.: "Influence of Damage of a Reinforced Concrete Beam on Change of its Behaviour." Proc. of the $5^{\text {th }}$ Int. Conf. on Structural Dynamics EURODYN 2002, Munich, 2002, p. 1451-1456.

[9] Toksoy T., Aktan A. E.: "Bridge-condition Assessment by Modal Flexibility." Experimental Mechanics, Vol. 34 (1994), No. 3, p. 271-278.

Ing. Tomáš Plachý, PhD.

phone: +420 224354482

e-mail: plachy@fsv.cvut.cz

Doc. Ing. Michal Polák, CSc. phone: +420224354476

e-mail:polak@fsv.cvut.cz

Czech Technical University in Prague

Faculty of Civil Engineering

Thákurova 7

16629 Praha 6, Czech Republic 